\title{
BRINQUEDOTECA VIRTUAL: LUDICIDADE E TECNOLOGIA NA FORMAÇÃO DE NOVOS PEDAGOGOS.
}

\author{
ÁGUA BRANCA/PI MAIO/2018 \\ FRANCISCO SOARES CAVALCANTE NETO \\ - UFRPE - jukacavalcante@hotmail.com \\ JULIANA REGUEIRA BASTO DINIZ - UFRPE - julianabdiniz.ead@gmail.com
}

Tipo: Relato de Experiência Inovadora (EI)

Categoria: Métodos e Tecnologias

Setor Educacional: EDUCAÇÃO SUPERIOR

\begin{abstract}
RESUMO
Este artigo tem como objetivo evidenciar e difundir o uso científico da brinquedoteca virtual no processo formativo de pedagogos como ferramenta tecnopedagógica assim como a sua inclusão no currículo acadêmico ao qual pode ser um desafio às instituições, aos docentes e ainda ao modelo existencial de educar. O trabalho pedagógico deve estar socialmente integrado à visão contemporânea ao tempo em que necessita de profissionais com ações inovadoras no contexto formativo das universidades proporcionando a inclusão de novas formas de conceber o processo de ensinoaprendizagem. As experiências aos quais os novos profissionais da pedagogia tomam contato devem ser desafiadoras, tendo nas Novas Tecnologias da Informação e Comunicação um fazer pedagógico atualizado e em constante inovação objetivando ações e intervenções que produzam novos conhecimentos e estes seja capaz de direcionar o processo formativo integral. A brinquedoteca virtual se torna um ambiente facilitador deste processo de integralidade formativa, pois, sendo um ambiente virtual formativo esta tecnologia apresenta várias possibilidades de trabalho, reflexões, contextos e de experimentos científicos de forma que teorias de aprendizagem sejam portabilizadas por meio desta ferramenta. As características lúdicas, a portabilidade, a conectividade somadas à didática do professor, podem transformar-se em um novo método educacional destinada ao pedagogo em formação.
\end{abstract}

Palavras-chave: Brinquedoteca Virtual, Formação, Pedagogia. 


\section{INTRODUÇÃO}

Com o advento da tecnologia os comportamentos sociais foram alterados e até mesmo inovados. O processo de adaptação e concepção destes novos modelos sociais encontra na educação a conexão necessária para a quebra de paradigmas e para a reorganização destes no contexto sociocultural. Para tanto os ambientes de aprendizagem deixaram de ser pensados unicamente em espaços físicos e foram idealizados também em ambientes virtuais para exercer influência formativa. Nesta perspectiva a Pedagogia é a ciência que se aproxima da realidade educacional no seu contexto formativo e esta tem como objeto de estudo a própria educação, ocupando-se do ato educativo e interessando-se pela prática educativa fazendo parte da atividade humana e da vida social do individuo; assim, proporcionar contato com instrumentos e contextos que integralizem pedagogicamente este processo educativo se faz latente em universidades. Oliveira (1999) reforça que:

A hipótese da tecnologia educacional revisitada refere-se ao [...] resgate da importância da tecnologia educacional, tal como defendida pelo tecnicismo pedagógico, mas tratada, agora, de forma diferente: - a partir de discussões relativas ao paradigma da empresa flexível e integrada; e (estreitamente ligado a isso) - em termos da consideração das tecnologias no trabalho escolar não apenas como método/recurso de ensino, (ou de gestão escolar), mas também como conteúdo/objeto de ensino. (Oliveira, 1999, p. 155).

Assim, a brinquedoteca virtual pode ser esta ferramenta flexível e integradora ao qual o autor referencia. Essas transformações que acontecem dentro e fora dos ambientes formativos, seja presencial ou virtual, constituem competências que por meio da comunicação, da experiência acumulada, dos saberes e dos modos de agir construídos e acumulados pela humanidade, transformam e são transformados à medida que são apresentados como inovadores, desafiadores, tecnológicos. Libâneo (2001, p.10) afirma que:

A Pedagogia, mediante conhecimentos científicos, filosóficos e técnico-profissionais, investiga a realidade educacional em transformação, para explicitar objetivos e processos de intervenção metodológica e organizativa referentes à transmissão/assimilação de saberes e modos de ação. Ela visa o entendimento, global e intencionalmente dirigido, dos problemas educativos e, para isso, recorre aos aportes teóricos providos pelas demais ciências da educação.

A atividade lúdica por meio das tecnologias tem provocado profundas transformações nos mais variados contextos, fato que exige novas posturas e atitudes no processo 
educacional exigindo propostas criativas e emancipadoras. Negar a contribuição da tecnologia para a educação é algo impensável, a diversidade de recursos e de possibilidades que emanam das Novas Tecnologias da Informação e Comunicação (NTICs) permitem alcançar um nível formativo ainda em processo de mensuração.

Neste espaço lúdico a abordagem pedagógica adotada utiliza a exploração livre, pois a ideia é o processo de adaptação de cada estudante no ambiente virtual da brinquedoteca, explorando as experiências de vida trazidas para a sala de aula, como também o retorno destes a seu contexto cultural. A grande possibilidade oportunizada pelos softwares educativos pode ser evidenciada por Valente (1993) quando diz que os ambientes de aprendizagem que utilizam o computador, este deve ser entendido como recurso para representar o conhecimento de outras formas, provocando uma mudança de conceitos preestabelecidos e possibilitando a busca e compreensão de novas ideias e valores.

Ainda segundo Valente (1993, p.13)

para implantação dos recursos tecnológicos de forma eficaz na educação são necessários quatro ingredientes básicos. O computador, o software educativo, 0 professor capacitado para usar o computador como meio educacional e o aluno. $O$ computador não e mais o instrumento que em ensina o aprendiz, mas a ferramenta com o qual o aluno o aluno desenvolve algo e, portanto, o aprendizado ocorre pelo fato de estar executando uma tarefa por meio do computador.

Portanto, a brinquedoteca virtual apresenta novas perspectivas de conectar a informação aos que a buscam, e que de forma desafiadora o uso desta tecnologia representa a possibilidade de campos de pesquisa e de novas dimensões pedagógicas no curso de pedagogia, pois está ligada às temáticas que procuram explicar o percurso da aprendizagem e suas inovações frente ao processo formativo.

Sendo assim o objetivo deste artigo é evidenciar e difundir o uso científico da brinquedoteca virtual no processo formativo de pedagogos como ferramenta tecnopedagógica assim como a sua inclusão no currículo.

\section{REFERENCIAL TEÓRICO}

Kishimoto (1998) argumenta que a primeira brinquedoteca apareceu nos Estados Unidos, em 1934, mas foi a partir de 1963 que as brinquedotecas foram surgindo em países como a África do Sul, Argentina, Austrália, Bélgica, Canadá, China, Estados 
Unidos, Finlândia, França, Grã-Bretanha, Itálica, Japão, Noruega, Portugal, Irlanda, Suécia, Suíça.

Roeder (2007) afirma que em 1981 foi criada a primeira brinquedoteca brasileira brinquedoteca Indianópolis, sob a direção de Nylse Helena da Silva Cunha, priorizando a brincadeira também com objetivos educacionais, realizando empréstimo de brinquedos.

Aqui se percebe que ocupando um ambiente físico a essência da brinquedoteca é de mover-se, de sair do espaço restrito comum e ir para a individualidade de cada ser, contextualizando sua vivência ao aprendizado de forma que brinquedo e realidade ganham sentido e podem juntos idealizar novos comportamentos socioeducativos.

Moran (1995) defende que é necessário buscar novas formas de ensino, visto que o campo da educação está permeado de mudanças.

A evolução da brinquedoteca física para o espaço virtual se dá pela necessidade de contextualização pedagógica ao qual o mercado de trabalho está se encaminhando, onde os novos modelos de interação social estão em pleno funcionamento, reservando as ferramentas tecnológicas o modelo existencial de aprendizado.

Para Lévy (1999, p. 51), "a tecnologia digital possibilitou um avanço considerável no que se refere à interação de crianças e adolescentes com atividades lúdicas e jogos, modificando a relação convencional e/ou tradicional da criança com brinquedo e brincadeira. Essas novas possibilidades têm ganhado também os espaços escolares, sendo incentivadas por programas governamentais que disponibilizam computadores para as escolas".

De acordo com Prensky (2001, p. 2), "os estudantes de hoje não são mais as mesmas pessoas para as quais nosso sistema educacional foi desenvolvido", e esta afirmação deve ser levada em consideração ao se pensar nos modelos educacionais dos quais as instituições de ensino de hoje se servem.

O que se observa é que o curso de pedagogia passa por reformulação ideológica constantemente, fato que analisado pela constante transformação que o mundo do conhecimento vem passando, se torna cabível a implementação de novas ferramentas e de novos olhares que de acordo com Masetto (2012):

Recentemente, professores universitários começaram a se conscientizar de que seu 
papel de docente do ensino superior, como exercício de qualquer profissão, exige capacitação própria e especifica que não se restringe a ter um diploma de bacharel, de mestre ou doutor, ou apenas o exercício de uma profissão. Exige isso tudo e competência pedagógica, pois é um educador, alguém que tem a missão de colaborar eficientemente para que seus alunos aprendam. Esse é seu ofício e compromisso. (p.15).

Para Vargas (1994), a tecnologia é hoje a atividade de transformação do mundo, resolução de problemas práticos, construção de obras e fabricação de instrumentos, baseada em conhecimentos científicos e por processos cientificamente controlados. Esta concepção eleva o debate cultural sobre o uso das tecnologias no processo formativo de educadores, os quais precisam dela para ações cotidianas, porém, o uso profissional destas ainda requer prática, aceitação e pedagogia.

Tajra (2002, p. 43), entende isso como um imperativo tecnológico e o define como "um estado no qual a sociedade se submete humildemente a cada nova exigência da tecnologia e utiliza sem questionar todo novo produto, seja portador ou não de uma melhora real".

Para Paiva (2011, p.1) "o homem esta irremediavelmente preso as ferramentas tecnológicas em uma relação dialética entre a adesão e acrítica ao novo".

Com a conexão proporcionada pela internet, o modo de pesquisar e organizar as informações mudou substancialmente, desafiando os modelos existentes de aprendizagem e alargando os horizontes quando o estudante deixa de ser um ser passivo e se torna um participante ativo cheio de informações e dúvidas.

Masetto (2010) afirma que a internet é um grande recurso de aprendizagem múltipla: aprende-se a ler, a buscar informações, a pesquisar, a comparar dados, analisa-los, criticá-los e organizá-los. Alunos e professores vão aprendendo, assim, a desenvolver sua criticidade.

Ao conceber a brinquedoteca virtual como um instrumento formativo, o olhar pedagógico de professores e pesquisadores pode ser direcionado a observar recursos de mídia, interface, ludicidade, portabilidade, concepção teórica, aplicabilidade.

Uma "rede" fruto de conexões entre pessoas, comunidades e conteúdos, constitui-se no aspecto fundamental da aprendizagem e pode ser qualificada enquanto uma rede bem sucedida quando apresenta as seguintes propriedades: descentralizadas; distribuídas; 
desintermediadas; com conteúdos e serviços des-integrados; democráticas; dinâmicas (fluidas) e inclusivas. (Downes apud Mota, 2009).

Assim, da mesma forma como as tecnologias estão em constante avanço, às teorias para entendimento destas evoluem também. Nas palavras de Siemens (2004) a tecnologia reorganizou o modo como vivemos, como nos comunicamos e como aprendemos e agora, a aprendizagem ocorre de várias maneiras, com destaque para a aprendizagem informal através de comunidades de prática, redes pessoais e também atividades relacionadas ao trabalho.

Nesta perspectiva, a brinquedoteca virtual adapta-se a diversas correntes teóricas enriquecendo sua função pedagógica e sendo esta uma característica que no processo de formação vai-se qualificando, modificando, evoluindo.

\section{PROCEDIMENTOS METODOLÓGICOS}

Construir indicadores que sirvam de conexão para novos conhecimentos é uma tarefa sinuosa e desafiadora. Fomentar a pesquisa e a construção cientifica requer observação, métodos, leitura e intenções sociais que motivem a difusão de experimentos e instrumentos quantiqualitativos para novas reflexões emergirem.

Segundo Teixeira (2010), para que se alcance uma educação de qualidade esta deve estar atrelada ao conhecimento. Dessa maneira, será possível a construção do conhecimento voltado para uma educação comprometida e, realmente, construtiva.

A construção deste artigo originou-se no programa de mestrado profissional em Tecnologia e Gestão em Educação a Distância ministrada na Universidade Federal Rural de Pernambuco (UFRPE) e que como produto da pesquisa idealizou-se um protótipo de brinquedoteca virtual. A pesquisa bibliográfica de vários autores que tratam do tema, e de reflexões que complementam o objetivo deste artigo fez o percurso metodológico deste artigo.

Assim, metodologia é uma preocupação instrumental. Trata das formas de se fazer ciência. Cuida dos procedimentos, das ferramentas, dos caminhos. A finalidade da ciência é tratar a realidade teórica e praticamente. Para atingirmos tal finalidade, colocam-se vários caminhos. Disto trata a metodologia (DEMO, 1985).

\section{APRESENTAÇÃO E DISCUSSÃO DOS RESULTADOS}


O contexto apresentativo da brinquedoteca virtual e sua interface ainda estão em processo de construção, tanto cientifica quanto academicamente. Os recursos incluídos no software educativo iram depender da objetividade ao qual a equipe colaborativa a desenvolve. Folque (2011) afirma que esta diversidade de ferramentas, por possuírem em sua composição vários recursos como sons, imagens e cores, ou seja, os meios visuais e audiovisuais favorecem a ludicidade e a aprendizagem significativa.

A pedagogia por ser uma ciência que diversifica e proporciona olhares e concepções diferentes, promove a inclusão de novos olhares sobre novas formas de "conectividade". Siemens (2004) desenvolveu e fundamentou uma nova teoria da aprendizagem intitulada de Conectivismo. Segundo o autor, as teorias existentes são insuficientes para compreender as características do individuo aprendiz do século XXI, face às novas realidades de desenvolvimento tecnológico e a sociedade organizada em rede. A BRINCOLIFE, protótipo idealizado na pesquisa de mestrado, utilizou-se desta concepção por definir de forma tecnopedagógica o ideal da brinquedoteca virtual no curso de pedagogia.

Contudo, para Siemens (2004) as teorias de aprendizagem comumente aceitas, tais como, behaviorismo, cognitivismo e construtivismo, são atualmente insuficientes para compreender a complexidade do processo de ensino-aprendizagem na atualidade, pois, suas concepções foram desenvolvidas em um contexto em que a aprendizagem não presenciava a inclusão das NTICs e seu impacto sobre o ser humano.

Por isso, as novas tecnologias utilizadas na educação exigem dos atores envolvidos no processo de assimilação de conhecimentos sejam capazes de conhece-las, entende-las e utiliza-las de diversas maneiras para formar profissionais com competências tecnológicas, sociais, criticas e reflexivos. Todavia, o que se nota é uma reação desconfortável e desfavorável de muitos educadores a inclusão de novas tecnologias. A concepção pedagógica da formação destes é predominante, fato que pode ser explicado por a grande maioria terem nascido antes da geração chamada "nativos digitais". Assim, a mudança de conceitos formativos passa pela legalização destes instrumentos tecnológicos nos currículos, nos planejamentos, nos planos de curso; a educação bancária citada por Freire (2011) ainda é uma realidade, não tão forte, mas insistente nas universidades.

Arroyo (1999) apresenta experiências de inovação educativa, proporcionando uma reflexão a respeito da base de formação curricular. Para tal, indica alguns traços dessas "inovações", a saber: pensar mudanças sob perspectivas hierarquizantes; diagnósticos negativos acerca do cotidiano escolar; solução centrada na "requalificação" de 
professores; pesquisas por amostragens possibilitando a definição de estratégias de ação; mudança pautada nos conteúdos e programas, entre outros.

Assim, a discussão sobre ludicidade, formação, currículo, tecnologia ganha mais um reforço com a brinquedoteca virtual e suas perspectivas. Estamos preparados para a pesquisa neste campo? Os educadores aceitam uma nova teoria de ensinoaprendizagem? $\mathrm{O}$ curso de pedagogia atende as exigências da sociedade do conhecimento?

\section{CONSIDERAÇÕES FINAIS}

As Novas Tecnologias da Informação e Comunicação estão em processo pedagógico de inovação. Novas ideias, novos softwares, novas pesquisas surgem cada dia e a cada congresso. Este artigo procura difundir a brinquedoteca virtual como uma ferramenta lúdica, didática, tecnopedagógica e cientifica tendo como laboratório o curso de Pedagogia, e o seu processo de formação de novos pedagogos. A sua inclusão depende da visão inovadora de vários profissionais que como uma "rede" idealizam um ambiente virtual capaz de adaptar-se às realidades tendo para seu efetivo uso, computador, celular, internet, professor, aluno dentre outros. Assim, surgem novas reflexões sobre cada componente e suas contribuições para a qualificação do processo formativo de novos pedagogos. Romper com praticas de exclusão é uma ação inovadora, pedagógica e educativa, seja para com os seres humanos, seja para com a tecnologia. Nesta perspectiva a brinquedoteca virtual e sua contemporaneidade abre espaço para mudanças educacionais que contemple a educação a partir das diferenças. Precisamos de um novo sujeito, de pedagogos capazes de refletir sobre o mundo real e virtual.

\section{REFERÊNCIAS}

ARROYO, M. G. Ciclos do Desenvolvimento Humano e formação de professores. Revista Educação e Sociedade. Campinas, n.68, p.143-162, 1999.

DEMO, P. Metodologia científica em ciências sociais. 3. ed. rev. e atual. São Paulo, SP: Atlas, 1995.

FREIRE, P. Pedagogia do oprimido. 50. ed. rev e atual :Rio de Janeiro: Paz e Terra, 2011.

FOLQUE, M. da A. Educação Infantil, tecnologia e cultura. Pátio - Educação Infantil, 
Porto Alegre, ano IX, n. 28, p. 8-11, jul. 2011.

KISHIMOTO, T. M. Diferentes tipos de brinquedotecas. In: Friedmann A. O direito de brincar: a brinquedoteca. São Paulo: Ed. Setembro; p. 53-63.1998.

LÉVY, P. Cibercultura. Tradução: Carlos Irineu da Costa. São Paulo: Editora 34, 1999.

LIBÂNEO, J. C. Pedagogia e pedagogos: inquietações e buscas. Educar. n. 17. ,p. 153-176. Editora da UFPR. Curitiba, 2001.

MASETTO, Marcos T. Competência Pedagógica do Professor Universitário. $2^{a}$. Ed. Rev. São Paulo: Summus, 2012.

MORAN, J. M. ; MASETTO, M. T. ; BEHRENS, M. A.

Novas Tecnologias e mediação pedagógica. 17ạ. Ed. São Paulo: Editora Papirus, 2010.

MORAN , J. M. O vídeo na sala de aula. Comunicação e educação. São Paulo. Vol. 2, p. 27- 35, Jan:/ abr. 1995

MOTA, J. C. Da Web 2.0 ao e-Learning 2.0: Aprender na rede. Dissertação de mestrado em Ciências da Educação, especialidade Pedagogia do e-Learning, Universidade Aberta, Portugal. Disponível em: Acesso em 14/05/2018.

OLIVEIRA, M.R.N.S. Tecnologias interativas e educação. Educação em Debate, Fortaleza, n. 37, p. 150-156. 1999.

PAIVA, V. L. M. de O. O Uso da Tecnologia no Ensino de Línguas Estrangeira: breve retrospectiva histórica. Acesso em: 14/05/2018.

PRENSKY, M. Digital Natives. Digital Immigrants. On the Horizon. MCB University Press, v. 9, n. 5, 2001.

ROEDER, S. Z. Brinquedoteca Universitária: processo de formação do pedagogo e contribuição para a prática pedagógica. 2007. Dissertação (Mestrado em Educação) Universidade Tuiuti do Paraná. Paraná, 2007.

SIEMENS, G. Conectivismo: Uma teoria de Aprendizagem para a idade digital. 2004. 
TAJRA, S. F. Informática na Educação. Novas Ferramentas Pedagógicas para o Professor da Atualidade. 4a . Ed. São Paulo, Érica Ltda, 2002.

TEIXEIRA, E. As três metodologias: acadêmica, da ciência e da pesquisa. 7. ed. Petrópolis, RJ: Vozes, 2010.

VALENTE, J. A. Computadores e conhecimento: repensando a educação. Campinas: UNICAMP. 1993.

VARGAS, M. Ciência, Técnica e Realidade. In: Para uma filosofia da tecnologia. São Paulo: Alfa Omega, 1994. 